\title{
Evaluación de la variabilidad
} genética en un ensayo de

\section{progenies de Pachira quinata usando marcadore moleculares}

\author{
Claudia Dolmus ${ }^{1}$, Ileana García ${ }^{1}$, Lourdes Callejas ${ }^{2}$ \\ 1. Tesista Universidad Nacional Autónoma de Nicaragua (UNAN-León). \\ 2. Docente investigador Universidad Nacional Autónoma de Nicaragua (UNAN-León )
}

Recibido: julio 2006 / aceptado: octubre 2006

ESTE ESTUDIO EVALUO LA VARIABILIDAD GENÉTICA ENTRE y dentro de progenies de Pachira quinata (Pochote), procedente de la localidad de Námbaras, Boaco, en un ensayo de progenies en el Centro de Mejoramiento Genético-Banco de Semillas Forestales de León, por medio de marcadores RAPDs. Un 100\% de las bandas polimórficas entre progenies y un $97.2 \%$ dentro de las progenies fueron generadas usando siete cebadores. Los dendrogramas obtenidos por UPGMA, tanto entre como dentro de progenies, demuestran una alta variabilidad $(75 \%)$ e, inclusive, diferencias entre genotipos provenientes de semillas de la misma planta madre. Estos resultados muestran también que existe una alta variabilidad dentro de la población de $P$. quinata.

Palabras clave: genética forestal- Nicaragua-evaluación / mejoramiento selectivo de árboles / semillas de árboles / Pochote-mejoramiento de la especie.

\section{Introducción}

Pachira quinata (Pochote) es una especie forestal que, por su alto valor comercial, ha sido sometida por años a una explotación severa. Esta especie se estableció en 1992 en el Centro de Mejoramiento Genético-Banco de Semilla Forestal (CMF-BSF), ubicado en el kilómetro 79, carretera Managua-León, como ensayo de progenies con semillas de árboles procedentes de Námbaras en Boaco (Ampié, 1992), junto con otros ensayos con otras especies como roble, eucalipto, etc., con el fin desarrollar programas de obtención de semillas mejoradas genéticamente para la producción forestal y reforestación de especies económicamente importantes. En la actualidad, el ensayo de Pachira quinata es considerado como prioridad por el CMG-BSF, ya que es uno de los primeros a evaluar para establecerlo como huerto semillero.

Debido a que los árboles de Pachira quinata establecidos en el CMG-BSF se pueden 
considerar una reserva genética de esta especie, es necesario conocer el grado de variabilidad genética que existe entre estos árboles, para garantizar la conservación de la variación genética existente, al momento de hacer la selección del material que será eliminado por raleo en el proceso de establecimiento del huerto semillero.

El desarrollo de la Biología Molecular permite métodos moleculares potentes como el RAPD (Random Amplified Polymorphic DNA), que detecta secuencias polimórficas amplificadas al azar, útiles como marcadores moleculares para determinar variaciones entre genotipos. Este estudio se realizó con el objetivo de evaluar la variabilidad genética del ensayo de progenies de Pachira quinata establecido en el CMG-BSF por medio de marcadores RAPDs.

Los resultados de la evaluación de la variabilidad genética entre los árboles establecidos en el ensayo de Pachira quinata del CMG-BSF que se obtengan mediante este estudio, permitirá garantizar que, en la selección de árboles para la creación del huerto semillero, se contará con árboles con características fenotípicas deseables y con la suficiente variación genética. De esta manera, se conservará su actual variabilidad, que es la fuente genética que garantizará la producción de semillas con una base de genes que capacite a los futuros árboles adaptarse a cambios en las condiciones ambientales, contribuyendo así a que el CMG-BSF produzca semillas de alta calidad para el sector forestal.

\section{Materiales y métodos}

\section{Colecta de muestra}

Se colectaron muestras de 62 árboles del ensayo de Pachira quinata establecido en el CMG-BSF. Los árboles fueron seleccionados al azar de cada fila del ensayo, colectándose muestras pertenecientes a 35 progenies distintas. Se utilizó un individuo por progenie (35) para determinar la diversidad genética entre progenies. En 17 de las 35 progenies se colectó más de un individuo hasta un máximo de cuatro, para determinar variabilidad genética dentro de progenies (44 muestras). Las muestras de cada árbol consistieron en hojas jóvenes que se dejaban en hielo mientras se trasladaban al Laboratorio de Genética Molecular del Departamento de Biología de la Facultad de Ciencias, de la Universidad Nacional Autónoma de Nicaragua-León (UNAN-León), donde se mantenían a -20?C por un período no mayor de 15 días antes de ser utilizadas para la extracción de ADN.

\section{Extracción de ADN}

Se modificó el protocolo propuesto por Möller et al. (1992), con el fin de extraer el ADN de Pachira quinata a partir de aproximadamente $60 \mathrm{mg}$ de tejido fresco, equivalente a 3 discos foliares realizados con la tapa del tubo eppendorf de $1.5 \mathrm{ml}$. Una vez triturado el tejido en $100 \mu \mathrm{l}$ de buffer de extracción (Tris $100 \mathrm{mM}$ pH =8, EDTA 10 mM, SDS 2\% y PVP 2\%) se le adiciona otros $400 \mu \mathrm{l}$ de buffer de extracción y $4 \mu \mathrm{l}$ de $\mu$-mercaptoetanol $14.4 \mathrm{M}$ para incubar por 30 min a $65 \mu \mathrm{C}$; luego se añade $140 \mu \mathrm{l}$ de $\mathrm{NaCl} 5 \mathrm{M}$ y $65 \mu \mathrm{l}$ de CTAB $10 \%$ y se continúa incubando por 10 min más.

Antes de separar el ADN de las proteínas y demás restos celulares por centrifugación a 
12,000 rpm por $10 \mathrm{~min}$ a $4^{\circ} \mathrm{C}$ con un volumen de cloroformo: alcohol isoamílico (24:1), se incuba el homogenizado en hielo por $20 \mathrm{~min}$ con $250 \mu \mathrm{l}$ de acetato de amonio $5 \mathrm{M}$.

El ADN se concentra y precipita con un volumen de isopropanol y luego el sedimento obtenido por centrifugación, es lavado dos veces con etanol 70\%, secado a temperatura ambiente y resuspendido en un volumen adecuado de TE (Tris $10 \mathrm{mM}$ y EDTA 1mM) para conservarlo a $-20{ }^{\circ} \mathrm{C}$, después de ser tratado con ARNasa $10 \mathrm{ng} / \mu \mathrm{l}$.

\section{Amplificaciones RAPDs}

Basándose en la técnica descrita por Williams et al., (1990), 25 ng de ADN fue amplificado en un volumen final de $25 \mu \mathrm{l}$ conteniendo buffer PCR 1X (50 mM de KCl, $1.5 \mathrm{mM} \mathrm{de} \mathrm{MgCl}_{2}, 10$ $\mathrm{mM}$ de Tris-HCl pH =9), $\mathrm{MgCl}_{2} 1.5 \mathrm{mM}$, dNTPs a $200 \mu \mathrm{M}$ de cada dATP, dCTP, dGTP y dTTP, cebador o primer $0.2 \mu \mathrm{M}$ y 1 unidad de Taq polimerasa. Las reacciones se realizaron en un termociclador modelo MiniCyclerTM M.J. Research programado para una desnaturalización inicial de 3 min a $92{ }^{\circ} \mathrm{C}$, seguida por 45 ciclos de desnaturalización 30 seg a $92^{\circ} \mathrm{C}$, hibridación 1 min a $37{ }^{\circ} \mathrm{C}$, elongación 1 min $72{ }^{\circ} \mathrm{C}$ y elongación final de 8 min a $72{ }^{\circ} \mathrm{C}$.

\section{Selección de cebadores}

Se utilizaron cuatro muestras distintas de ADN de Pachira quinata para ensayar 45 cebadores pertenecientes al Laboratorio de Genética Molecular, con el fin de seleccionar los cebadores que, además de amplificar un patrón de bandas bien definido, generen mayor cantidad de polimorfismos entre las muestras ensayadas, definiendo así el poder usar un número menor de cebadores en las amplificaciones RAPDs con el total de las muestras de ADN a analizar en este estudio.

\section{Análisis de datos}

Utilizando el paquete estadístico NTSYS (Numerical Taxonomy and Multivariate Analisys System) versión 1.5 (Rohlf, 1993), se construye con los marcadores RAPDs generados en las amplificaciones realizadas entre y dentro de progenies, una matriz presencia-ausencia, la cual se utiliza para obtener la matriz de similitud utilizando el coeficiente de Jaccard. A la matriz de similitud se le aplica un análisis de agrupamiento por medio del método UPGMA (Unweighted Pair Group Method Average). La agrupación resultante se representa gráficamente en una estructura arborescente o dendrograma a través del cual se estima la variabilidad genética de las muestras analizadas.

\section{Resultado y discusión}

Debido a que existe un gran número de cebadores oligonucleótidos cortos de secuencia arbitraria, se debe realizar una cuidadosa selección de los cebadores a utilizar (Loo et al., 1999), ensayando para cada nueva especie a analizar por la técnica RAPD, una prueba piloto en unos cuantos genotipos con diferentes cebadores bajo las condiciones de reacción óptima, para asegurar la obtención de productos de amplificación que generen patrones de bandas identificables, en los cuales se detecten los polimorfismos (Khasa et al., 1996). 
Del total de 45 cebadores ensayados en este estudio, 12 amplificaron : G-05, I-06, K-03, S07, R-02, B-10, N-09, F-01, U-16, H-07, K-12 y B-05, utilizándose los últimos siete para las amplificaciones de todas las muestras de Pachira quinata . En la Ilustración 1 se muestran los resultados de la amplificación ensayada con N-09.

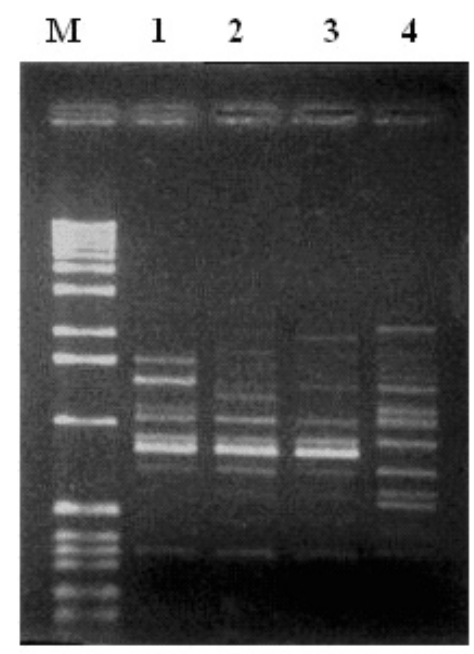

Ilustración 1. Patrones de bandas RAPDs generadas con el cebador N-09 en cuatro muestras de Pachira quinata (líneas 1 a 4). Línea M es el Marcador Ladder 1 ug/ $\mu \mathrm{l}$.

Con los siete cebadores utilizados en este estudio, se generaron un total de 82 bandas entre 35 progenies (35 muestras) y 72 bandas dentro de 17 progenies (44 muestras), con un rango de peso molecular entre 200 a 3,000 pb, lo cual corresponde a las distancias límite de los cebadores, citado por autores como Whitkus et al. (1994).

Todos los cebadores generaron un alto número de bandas polimórficas siendo el mínimo siete con H-07 y N-09, dentro de progenies y el máximo 14 con F-01 entre progenies. Esta alta cantidad de polimorfismos en las muestras y el hecho de casi todas las bandas fueron polimórficas (100\% entre progenies y $97.2 \%$ dentro de progenies) refleja una alta variabilidad entre y dentro de progenies (Cuadro 1). 
Cuadro 1. Cantidad de bandas producidas de las amplificaciones RAPDs con siete cebadores entre 35 progenies (familias) y dentro de 17 progenies de Pachira quinata

\begin{tabular}{|c|c|c|c|c|c|c|c|}
\hline \multirow{2}{*}{ Cebadores } & \multirow{2}{*}{ Secuencia 5' $\rightarrow$ 3, } & \multicolumn{2}{|c|}{ Bandas Monomórficas } & \multicolumn{2}{|c|}{ Bandas Polimórficas } & \multicolumn{2}{c|}{ Total de Bandas } \\
\cline { 3 - 8 } & familias & $\begin{array}{c}\text { Dentro de } \\
\text { familias }\end{array}$ & $\begin{array}{c}\text { Entre } \\
\text { familias }\end{array}$ & $\begin{array}{c}\text { Dentro de } \\
\text { familias }\end{array}$ & $\begin{array}{c}\text { Entre } \\
\text { familias }\end{array}$ & $\begin{array}{c}\text { Dentro de } \\
\text { familias }\end{array}$ \\
\hline N-09 & TGC CGG GTT G & 0 & 2 & 10 & 7 & 10 & 9 \\
\hline B-10 & CTG CTG GGA C & 0 & 0 & 13 & 12 & 13 & 12 \\
\hline U-16 & CTG CGC TGG A & 0 & 0 & 12 & 11 & 12 & 11 \\
\hline F-01 & ACG GAT CCT G & 0 & 0 & 14 & 9 & 14 & 9 \\
\hline H-07 & CTG CAT CGT G & 0 & 0 & 8 & 7 & 8 & 7 \\
\hline K-12 & TGG CCC TCA C & 0 & 0 & 12 & 13 & 12 & 13 \\
\hline B-05 & TGC GCC CTT C & 0 & 0 & 13 & 11 & 13 & 11 \\
\hline Total & & 0 & 2 & 82 & 70 & 82 & 72 \\
\hline Media & & & 0.28 & 11.7 & 10 & 11.7 & 10.28 \\
\hline
\end{tabular}

Estos resultados coinciden con lo que menciona Nesbitt et al. (1997), quienes afirman que después de un rastreo inicial para seleccionar los cebadores que detectan polimorfismo entre individuos cercanamente relacionados, parece que no es necesario utilizar un gran número de ellos para evaluar la variabilidad.

Existen algunos estudios RAPD que han utilizados pocos cebadores $(<7)$ para estimar la variabilidad genética de especies forestales, como el realizado con cuatro cebadores en Ceratitis capitata obteniendo 74 bandas polimórficas (Baruffi et al., 1995); con seis cebadores en Licuala glabra se generaron 87 polimorfismos (Loo et al., 1999); y con seis cebadores en Sabal mexicana resultaron 39 bandas polimórficas (Guido, 2005), aunque este último estudio efectuado en el Laboratorio de Genética Molecular (UNAN-León) que realizó una estimación preliminar de la variabilidad en la palma de techo, recomienda usar al menos 50 a 100 o más marcadores polimórficos, según cita Nybom et al., (2000), para obtener estimaciones fiables de la variabilidad genética.

El dendrograma (Ilustración 2) obtenido de las muestras analizadas entre progenies (35) diferenció todas las progenies entre sí (ninguna de las muestras presentan 100\% de similitud) y a la vez las relaciona en un solo grupo con un 25\% de similitud genética, lo que significa que existe un alto porcentaje de variabilidad genética entre progenies de $75 \%$. Al separarse estas progenies en dos subgrupos principales, mantienen siempre alta variación genética dentro de los subgrupos, siendo las progenies 55 y 58 las que más cercanamente se relacionan, con un 58\%, lo que significa que la diferencia entre las dos muestras más cercanamente relacionadas, es mayor del $42 \%$. 


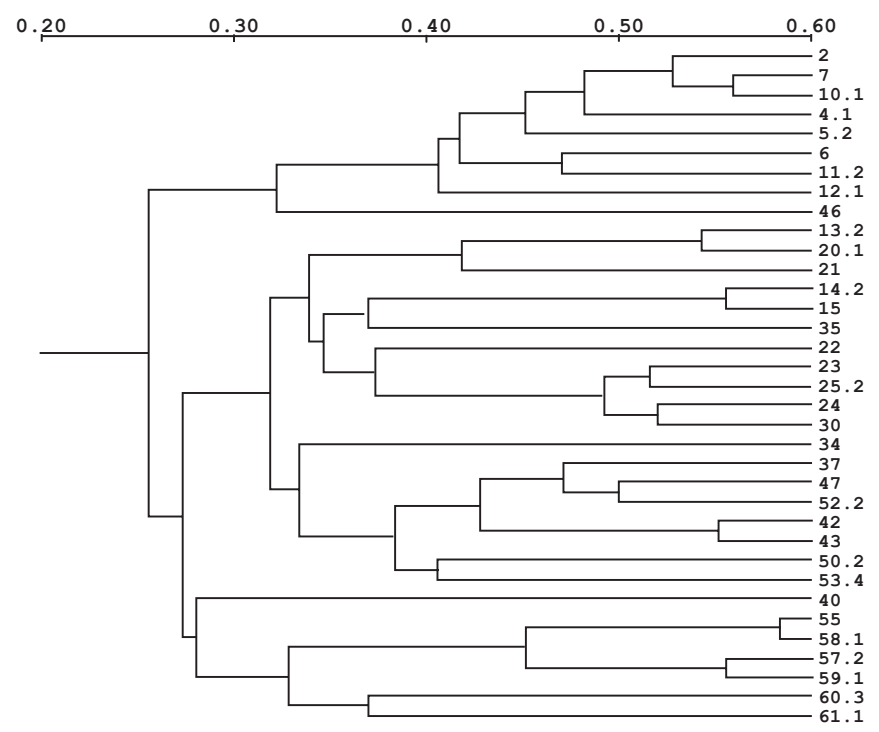

Ilustración 2. Dendrograma generado con el análisis de agrupamiento por similitud genética entre 35 progenies de Pachira quinata. (Las muestras con decimal indican el número de individuo utilizado en el análisis entre progenies, para aquellas muestras con más de un individuo).

Los resultados de variabilidad detectada con el análisis de agrupamiento de los marcadores RAPDs entre las 35 progenies utilizadas en este estudio, no sólo determinan la existencia de una alta variabilidad en los árboles de Pachira quinata establecidos en el CMG-BSF, sino también, de manera indirecta estima que existe una alta variabilidad dentro de la población de la cual provienen, ya que tomando en cuenta la información brindada por el Ingeniero Eduardo Ampié (2005), según la cual los árboles de Pachira quinata establecidos en el CMG-BSF son individuos que proceden todos de semillas colectadas de una misma población natural de Námbaras (Boaco), donde fueron seleccionados de árboles a distancia mínima de 100 metros entre árboles, se puede considerar las 35 progenies como una muestra de dicha población.

Debido a la utilidad de la técnica RAPD para detectar variación dentro de poblaciones cuando ésta existe (Vicario et $a l$., 1995), algunos investigadores la han utilizado para demostrar que las poblaciones naturales de especies de árboles tropicales mantienen un alto nivel de variación genética dentro de las poblaciones (Chalmers et al., 1992), al aplicar esta técnica en estudios de diferenciación genética en poblaciones como Theobroma cacao (Russell $e t$ al., 1993), Abies alba y Abies nebrodensis (Vicario et al., 1995).

Además, estos resultados están en concordancia con lo señalado por Hamrick (1990), en el sentido de que las plantas maderables perennes de larga vida y fecundación cruzada exhiben gran variabilidad dentro de las poblaciones (citado por Chalmers et al., 1992) lo cual ha sido demostrado en estudios como los realizados en poblaciones de Ilex paraguariensis 
(Gauer \& Molina, 2000) y en Pinus oocarpa (Díaz, 2001), donde encontraron una positiva asociación entre estas características con la alta variabilidad detectada por RAPD dentro de estas poblaciones naturales.

Las flores hermafroditas pero altamente incompatibles de Pachira quinata (Stevens et al., 2001) permiten un sistema de reproducción por fecundación cruzada lo que, al parecer, causa un alto grado de variación, inclusive entre individuos muy cercanamente relacionados como las progenies provenientes de semillas de la misma planta madre, lo que se determinó en este estudio a través del análisis de agrupamiento dentro de progenies, donde se diferenciaron los genotipos analizados de una misma progenie con un considerable porcentaje de variabilidad genética.

En el dendrograma (Ilustración 3) que analiza la relación dentro de 17 progenies (con un total de 44 muestras), siempre se relacionan todas las muestras en un solo grupo con aproximadamente un 25\% de similitud y, a la vez, se separan también en dos subgrupos principales en donde cada subgrupo mantiene la tendencia de agrupar individuos pertenecientes a una misma progenie, a excepción de una muestra de la progenie 20 (20.3), aunque la agrupación es de forma disgregada en cada subgrupo.

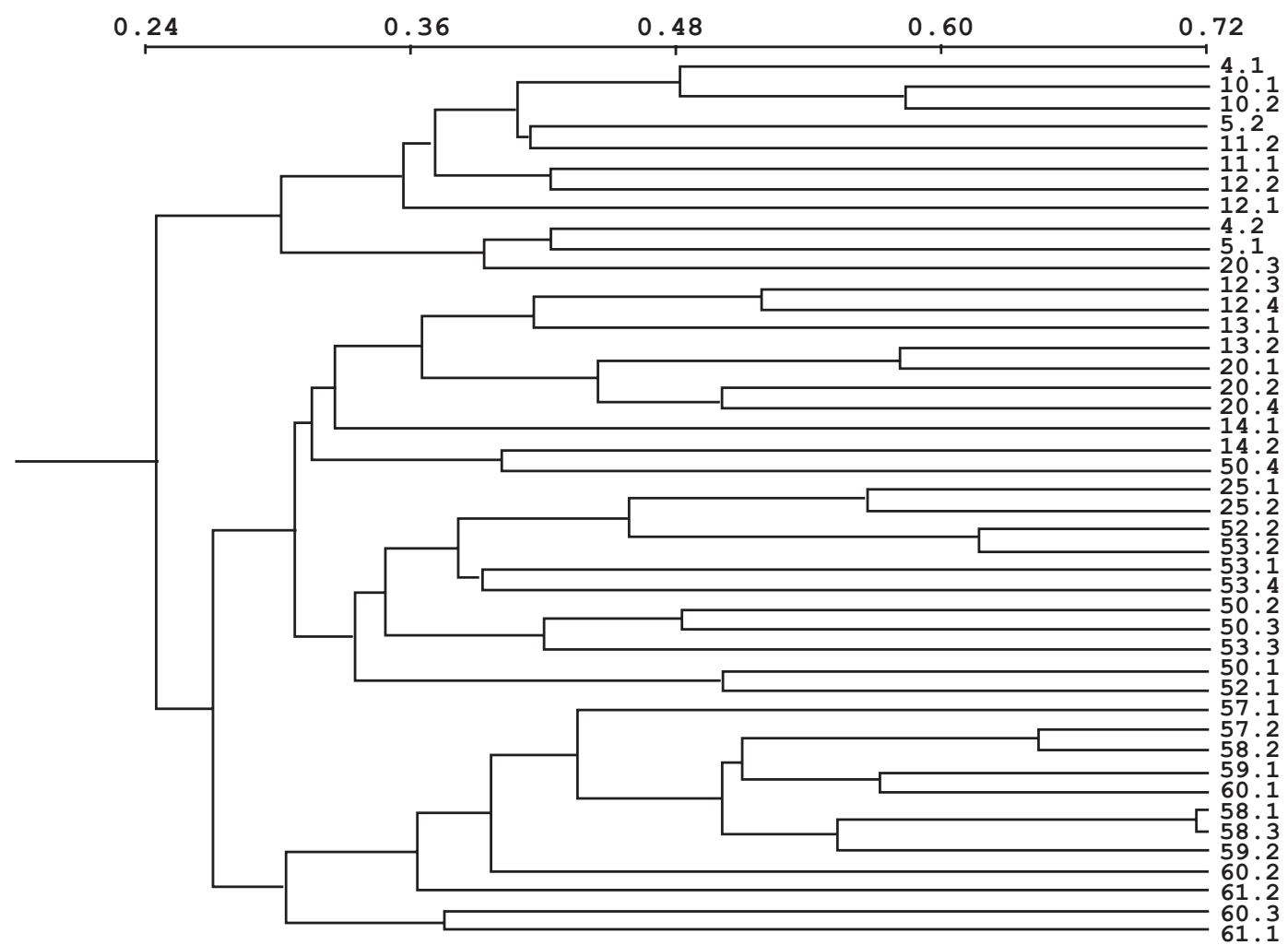

Ilustración 3. Dendrograma generado con el análisis de agrupamiento por similitud genética dentro de 17 progenies de Pachira quinata. 
La falta de asociación en un solo grupo de los individuos pertenecientes a una misma progenie (a excepción de las progenies 10 y 25) se debe a que ninguno de los cebadores utilizados presentó un patrón de bandas que unificara a los genotipos como miembros de una misma progenie, ya que no se generaron bandas que estuvieran presentes en una única progenie y bandas presentes en individuos de una progenie, a veces se presentaban en individuos de otras progenies distintas. Esto puede ocurrir porque, como individuos de una misma especie, comparten secuencias de bandas. Además, es bien sabido que bandas de diferentes individuos que se presentan en la misma posición en el gel no son necesariamente homólogas; o sea, no necesariamente provienen del mismo locus, ya que pueden ser originados por diferentes secuencias, pero con igual peso molecular, por lo que aparecen en la misma posición en el gel de electroforesis (Baruffi et al., 1995). Por la técnica Southern Blott se puede detectar si las bandas monomórficas generadas por un cebador son del mismo locus o no (Loo et al.,1999).

También, en las amplificaciones con la técnica RAPD, puede suceder que bandas de un mismo individuo que no son homólogas, pueden coemigrar en la misma posición en el gel. En el caso de las especies con grandes genomas, tienen mucho ADN repetitivo y, por eso, los cebadores simples que se usan en la técnica RAPD pueden amplificar muchos fragmentos, los cuales pueden migrar cerca uno del otro y probablemente también coemigran. Usar largos tiempos de corrida para separar los fragmentos durante la electroforesis puede reducir la posibilidad de visualizar un fragmento no homólogo como homólogo (Hurme and Savolainen, 1999). A pesar de estas limitantes, los polimorfismos que genera la técnica RAPD por presencia y ausencia la hacen una herramienta muy utilizada para cuantificar la variabilidad genética entre individuos o especies (Williams et al., 1990).

La variabilidad genética permite a los genotipos reaccionar y adaptarse a los cambios del medio ambiente (FAO, DFSC e IPGRI, 2002). Los resultados de este estudio demuestran que existe una gran cantidad de variación genética entre y dentro de las progenies del ensayo de Pachira quinata del CMG-BSF, lo que garantiza que se pueden seleccionar los mejores fenotipos y, a la vez, mantener entre ellos suficiente variabilidad genética en el huerto semillero que se establezca en este ensayo. Para ello, se deben contrastar los resultados de este estudio con las características morfológicas de interés comercial.

Tomando en cuenta que en programas de conservación de recursos genéticos se deben incluir también árboles con características fenotípicas no deseadas para la producción, como por ejemplo árboles de menor altura, porte defectuoso etc., que pueden constituir una reserva genética valiosa que les confiera características como resistencia a la sequía, plagas y enfermedades, etc., se recomienda considerar los resultados de este estudio para conservar la valiosa reserva de Pachira quinata existente en el ensayo del CMG-BSF manteniendo al menos una representación por progenie y cierta cantidad de individuos dentro de las progenies al momento de realizar el raleo en el establecimiento del huerto semillero. Además, se debe considerar la realización de futuros análisis RAPDs con muestras de Pachira quinata de diferentes orígenes geográficos, ya que se desconoce la distribución de la variación genética entre las poblaciones de esta especie en el país. 


\section{Agradecimientos}

Agradecemos a la Comunidad Autónoma de Madrid (CAM) por financiar este estudio desarrollado dentro del Programa de Genética Molecular del trienio 2003-2005, perteneciente al hermanamiento con la Universidad Alcalá de Henares (UAH)-Universidad Nacional Autónoma de Nicaragua-León (UNAN-León). Damos las gracias también, al Ingeniero Eduardo Ampié, de la Dirección de Semillas Forestales del Ministerio Agropecuario Forestal (MAGFOR), por la información brindada sobre el establecimiento del ensayo de Pachira quinata donde se realizó este estudio, y al Centro de Mejoramiento Genético-Banco de Semillas Forestales, especialmente a la Licenciada Esperanza Toruño y a Raúl Castro por darnos acceso al ensayo para realizar la colecta de muestras. Además, agradecemos la colaboración brindada por David Cerda durante el tiempo de la colecta de muestras para este estudio.

\section{Referencias bibliográficas}

-AMPIÉ, E. (1992). Ensayo de 60 descendencia de Bombacopsis quinata, s.l. Sección de Mejoramiento Genético y Conservación Forestal.

-AMPIÉ, E. (2005). Ensayo de pochote (entrevista) Managua, MAGFOR

-BARUFFI, L. et al., (1995). "Polymorphisms within and between populations of Ceratitis capitata: comparison between RAPD and multilocus enzyme electrophoresis data", Heredity. Vol. 74, 425-437.

-CHALMERS, K. et al., (1992). "Detection of genetic variation between and within populations of Gliricida sepium and G. maculata using RAPD markers", Heredity, Vol. 69, 465-472. -DÍAZ, V., (2001). Caracterización de la Diversidad Genética de Poblaciones Naturales de Pinus oocarpa de Nicaragua a través de Marcadores Moleculares, Tesis doctoral, Alcalá, España, Universidad de Alcalá de Henares.

-FAO (Organización de las Naciones Unidas para la Agricultura y la Alimentación); DFSC (Centro de Semillas de Árboles Forestales de Danida) e IPGRI (Instituto Internacional de Recursos Fitogenético) (2002). Conservación y Ordenación de Recursos Genéticos Forestales: En Bosques Naturales Ordenados y Áreas Protegidas in situ. s.l. Instituto Internacional de Recursos Filogenéticos.

-GAUER, L. y CAVALLI-MOLINA, S., (2000). Genetic variation in natural populations of mate (Ilex paraguariensis A. St.-Hill. Aquifoliaceae) using RAPD markers", Heredity, Vol. 84, 647-656.

-GUIDO, D., (2005). Estudio preliminar de la diversidad genética entre 16 procedencias de Sabal mexicana Mart, del Pacifico de Nicaragua, aplicando la técnica RAPD, Tesis de licenciatura, León, Universidad Nacional Autónoma de Nicaragua-León.

-HURMER, P. y SAVOLAINEN, O. (1999). "Comparison of homology and linkage of random amplified polymorphic DNA (RAPD) markers between individual trees of Scots pine (Pinus sylvestris L.)" Molecular Ecology, Vol. 8, 15-22.

-KHASA, P. y DANCIK, B. (1996). "Rapid identification of white-Engelmann spruce species by RAPD markers", Theor Appl Genet, Vol. 92, 46-52.

-LOO, A. et al., (1999). "Population Analysis of Licuala glabra Grif, Var, glabra (Palmae) using RAPD Profiling". Annals of Botany, Vol. 84, 421-427. 
-MÖLLER, E. et al., (1992). "A simple and efficient protocol for isolation of high molecular weight DNA from filamentous fungi, fruit, bodies, and infected plant tissues”, Nucleic Acid Research, Vol. 20, 6115-6116.

-NESBITT, K. et al., (1996). "Fingerprinting and Pedigree Analysis in Eucalyptus globulus using RAPD”. Silvae Genetica. Vol. 46, 6-11.

-NYBOM, H. y BARTISH, I. (2000). "Effects of life history traits and sampling strategies on genetic diversity estimates obtained with RAPD markers in plants". Vol. 3/2, 93-114.

-ROHLF, F. (1993). NTSYS-pc: Numerical Taxonomy and Multivariate Analysis System, Version 1.50. N.Y. Exeter Software, Setauket.

-RUSSELL, J. et al., (1993). "Genetic differentiation of cocoa (Theobroma cacao L.) populations revealed by RAPD analysis”. Molecular Ecology, Vol. 2, 89-97.

-STEVENS, W. et al., (2001). Flora de Nicaragua, Estados Unidos, Editorial Missouri Botanical Garden Press, 1를 edición.

-VICARIO, F. et al., (1995). "Allozyme, chloroplast DNA and RAPD markers for determining genetic relationships between Abies alba and the relic population of Abies nebrodensis". Theor Appl Genet, Vol. 90, 1012-1018.

-WHITKUS, R.; DOEBLEY, J. y WENDEL, J. (1994). DNA-based markers in plants, Holanda. Editorial Dower, 1aㅡ edición.

-WILLIAMS, J. et al., (1990). "DNA polymorphisms amplified by arbitrary primers are useful as genetic markers”. Nucleic Acids Research, Vol. 18,6531-6535. 